\title{
Porous SiOCH Thin Films Obtained by Foaming
}

\author{
Supporting Information
}

Julien El Sabahy, Gaël Castellan, Florence Ricoul and

\author{
Vincent Jousseaume*
}

Univ. Grenoble Alpes, F-38000 Grenoble, France,

CEA, LETI, MINATEC Campus,

F-38054 Grenoble, France. 


\section{I- Porosity measurements and pore size distribution}

After the crust removal, Ellipsometric porosimetry (EP) was performed on foamed $\mathrm{SiOCH}$ films. This technique based on the refractive index change during adsorption and desorption of organic vapors, provides information on thin film porosity and pore size distribution. Figure S1 presents a typical EP result for a SiOCH (3MS) thin film deposited at $150^{\circ} \mathrm{C}$ and cured for $7 \mathrm{~min}$ (328 nm thick).

S1a)

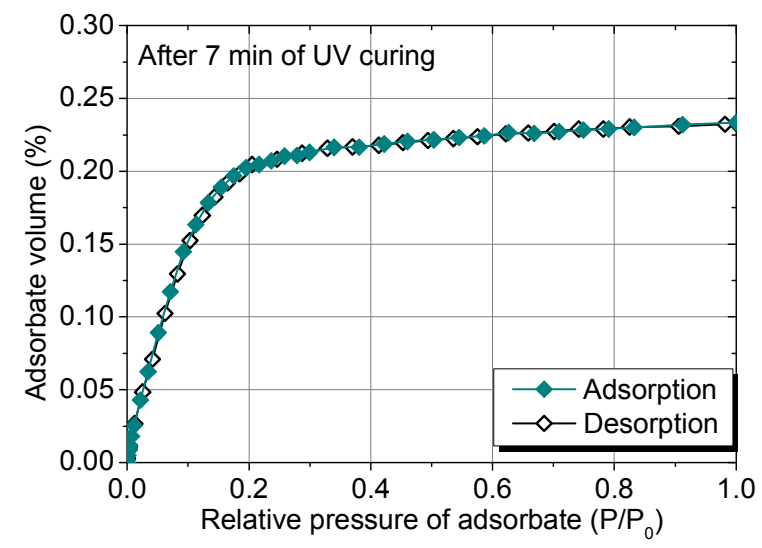

$\mathrm{S} 1 \mathrm{~b})$

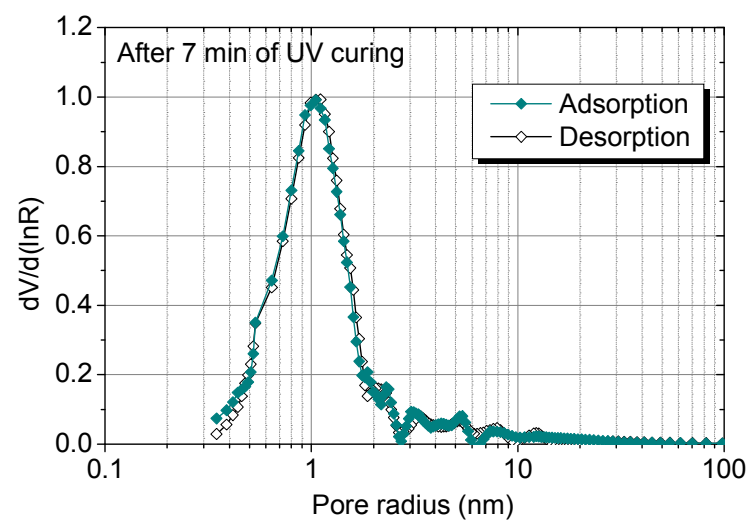

Figure S1a. Adsorption and desorption isotherm obtained by ellipsometric porosimetry on a $\mathrm{SiOCH}(3 \mathrm{MS})$ thin film deposited at $150^{\circ} \mathrm{C}$ and cured for $7 \mathrm{~min}\left(328 \mathrm{~nm}\right.$ thick). The $\mathrm{SiO}_{2}$ 
capping layer was removed before the EP measurements. S1b. Pore size distribution deduced from the isotherm using the Kelvin model.

As shown in Figure S1a, the toluene isotherm is reversible and concave to the relative pressure axis. A steep rise is observed for low relative pressure, before reaching a plateau. This shape corresponds to a "type 1" isotherm of the IUPAC classification which is typical of a microporous film [SI1]. In this example, a porosity of $23 \%$ is reached. No hysteresis loop is observed, indicating that the pore size is lower than $2 \mathrm{~nm}$ [SI2]. This is confirmed in Figure $\mathrm{S} 1 \mathrm{~b}$ where pore radius distribution is represented (this distribution being determinated using the Kelvin model [SI3]).

The film refractive index variations during a toluene adsorption/desorption cycle are presented in Figure S2a for a SiOCH (OMCTS) thin film (foamed for $12 \mathrm{~min}, 616 \mathrm{~nm}$ thick). These isotherms are more complex than in the case of SiOCH (3MS):

- An important hysteresis is observed between the adsorption and desorption isotherms.

- The thickness variations during toluene adsorption are very important (more than $15 \%$ of swelling.

- Both thickness and refractive index after toluene adsorption /desorption cycle do not reach their initial values.

During the adsorption step, no important change is observed below a relative pressure of 0.2. Then, the refractive index increases until a plateau is reached at a relative pressure close to 0.85. The film thickness decreases between relative pressure of 0.5 and 0.8 , indicating toluene condensation. This behavior was observed previously and interpreted as being induced by capillary forces (see [SI4] for mesoporous silicates and references therein). After the 
completion of toluene condensation, the film thickness increases probably due to the relaxation of capillary forces and the formation of toluene multilayer at the top of the filled film. This film swelling is also an indication of the "polymeric-like" nature of these highly porous $\mathrm{SiOCH}$. Then, the pore size distribution using the Kelvin model is more difficult to determine due to this complex behavior.

S2a)

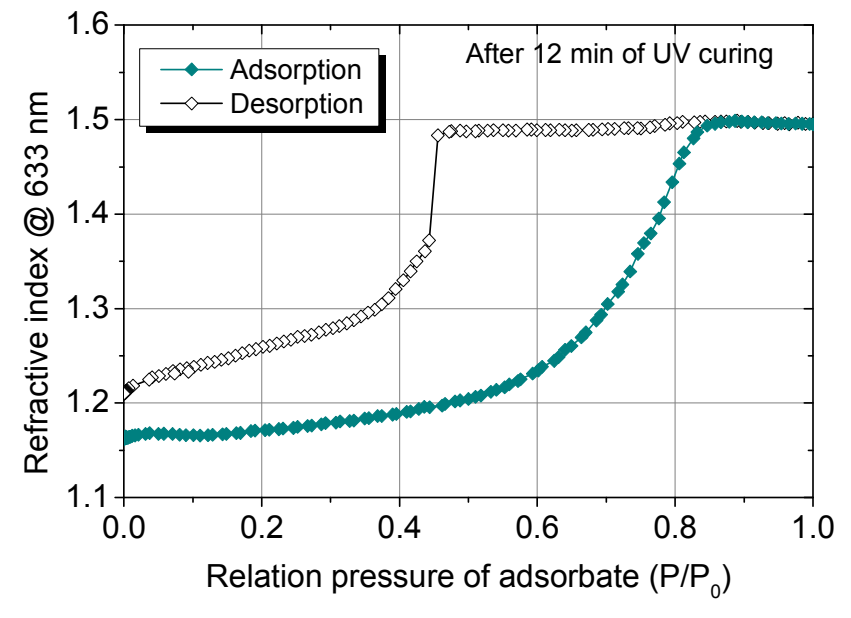

S2b)

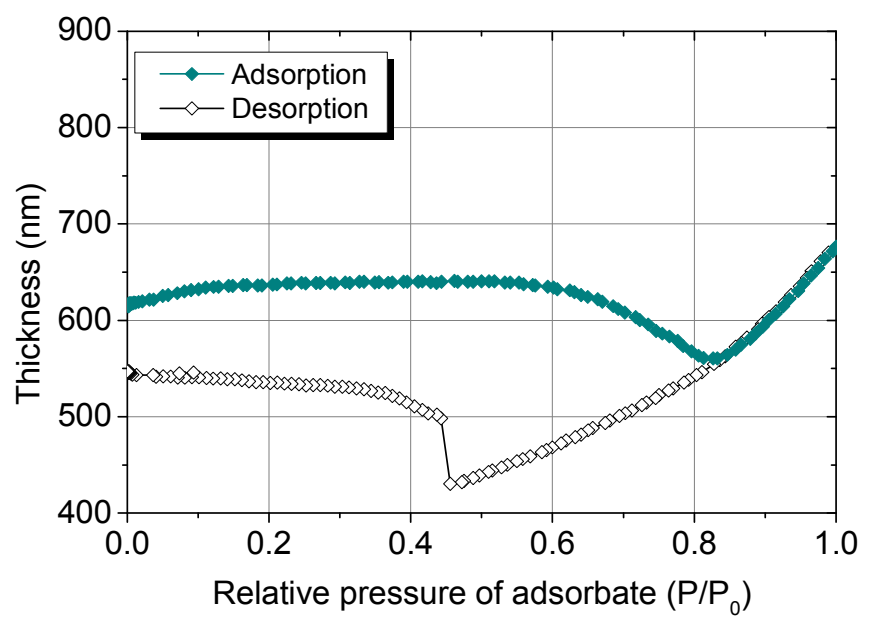

Figure S2a. Adsorption and desorption isotherm obtained by ellipsometric porosimetry on a $\mathrm{SiOCH}(\mathrm{OMCTS})$ thin film deposited at $150^{\circ} \mathrm{C}$ and cured for $12 \mathrm{~min}\left(616 \mathrm{~nm}\right.$ thick). $\mathrm{The}^{\mathrm{SiO}_{2}}$ 
capping layer was removed before the EP measurements. S2b. Variations of the film thickness during the EP experiment.

A difference of film thickness before and after the adsorption - desorption cycle (at $\left.\mathrm{P} / \mathrm{P}_{0}=0\right)$ is also observed. This phenomenon can be attributed to the presence of solvent residues (toluene) difficult to remove from the materials (the refractive index does not reach its initial value after the cycle, confirming also the presence of toluene in the film). This result is reproducible and is observed only on highly porous films (porosity $>50 \%$ ). We can expect that toluene molecules trapped in the polymeric-like structure of the skeleton are more difficult to remove after the desorption step. A slight heating at $200^{\circ} \mathrm{C}$ for few minutes allows to recover the initial refractive index and film thickness.

\section{II- Film expansion estimated by EP}

Thickness variations during EP experiments are also observed for $\mathrm{SiOCH}$ (3MS) thin films. Results are reported in Figure S3 for different deposition temperatures. A thickness increase of the SiOCH thin films is observed during the adsorption of toluene. The same behavior is observed whatever the thickness investigated (from $80 \mathrm{~nm}$ to $500 \mathrm{~nm}$ ). The swelling is higher for films deposited at low temperature, suggesting a lower stiffness. This trend is relevant when compared to previous studies of $3 \mathrm{MS}$ deposited from $200^{\circ} \mathrm{C}$ to $400^{\circ} \mathrm{C}$, where the Young's modulus (which can be deduced from these curves [SI5]) is showed to increase with temperature deposition [SI6]. Consequently, a film deposited at low temperature presents a higher swelling potential. It may be one reason why foaming is taking place more easily for these films. 


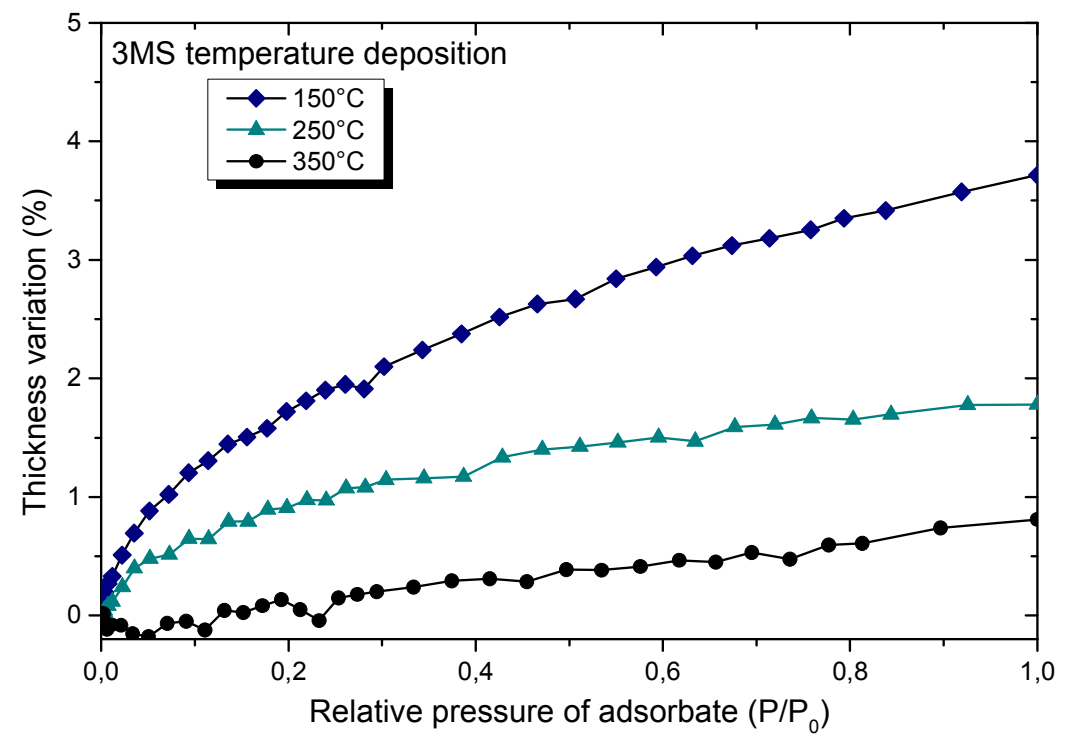

Figure S3. Film thickness variation as function of the relative pressure of toluene (adsorption) for $\mathrm{SiOCH}(3 \mathrm{MS})$ films deposited at different temperatures.

\section{III- X-Ray Reflectivity (XRR)}

Figure S4 shows an example of data fitting of the XRR spectra for a 3MS thin film after 9 min of UV curing and crust removal. XRR data analyses were performed with JVXRRS Reflectivity software using film stoichiometry determined by Rutherford Backscattering Spectrometry and Nuclear Reaction Analysis. In this example, the film thickness of the sample is $157 \mathrm{~nm}$ (in good agreement with the film thickness estimated by ellipsometry $=160$ $\mathrm{nm}$ ), the roughness is $0.5 \mathrm{~nm}$ and the density is $0.95 \mathrm{~g} . \mathrm{cm}^{-3}$. 


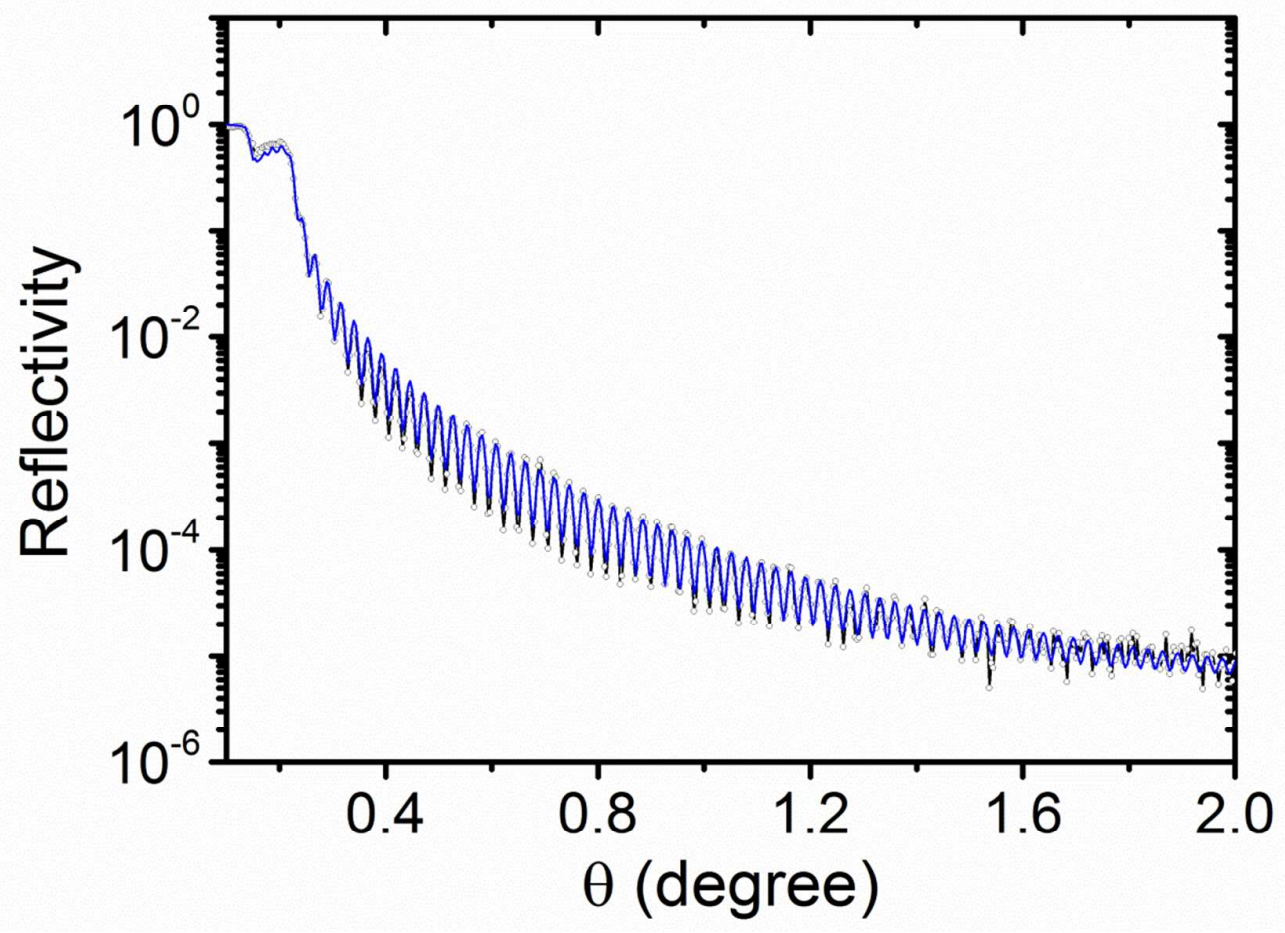

Figure S4. Experimental (black + dot) and fitted (blue line) X-ray reflectivity pattern of a SiOCH (3MS) films after UV curing (9 min) and crust removal.

\section{REFERENCES}

[SI1] Rouquerol, F.; Rouquerol, L.; Sing, K. S. W.; Adsorption by Powders and Porous Solids: Principles, Methodology, and Applications, 1999, Academic Press, San Diego.

[SI2] Dultsev, F. N.; and Baklanov, M. R. Nondestructive Determination of Pore Size Distribution in Thin Films Deposited on Solid Substrates. Electrochem. Solid-State Lett. 1999, 2, 192-194.

[SI3] Thomson, W. On the Equilibrium of Vapour at a Curved Surface of Liquid. Proc. $R$. Soc. Edinb. 1872, 7, 63-68. 
[SI4] Dendooven, J.; Devloo-Casier, K.; Levrau, E.; Van Hove, R.; Pulinthanathu Sree, S.;

Baklanov, M. R.; Martens, J. A.; Detavernier, C. In Situ Monitoring of Atomic Layer Deposition in Nanoporous Thin Films Using Ellipsometric Porosimetry. Langmuir 2012, 28, 3852-3859.

[SI5] Mogilnikov, K. P.; Baklanov, M. R. Determination of Young's Modulus of Porous Low-k Films by Ellipsometric Porosimetry. Electrochem. Solid-State Lett. 2002, 5, F29-F31.

[SI6] Wong, T. K. S.; Liu, B.; Narayanan, B.; Ligatchev, V.; Kumar, R. Investigation of Deposition Temperature Effect on Properties of PECVD SiOCH Low-k Films. Thin Solid Films 2004, 462-463, 156-160. 